\title{
SiC AND GaAs EMITTERS AS SELECTIVE TERAHERTZ RADIATION SOURCES
}

\author{
J. Požela, E. Širmulis, K. Požela, A. Šilènas, and V. Jucienė \\ Semiconductor Physics Institute, Center for Physical Sciences and Technology, A. Goštauto 11, LT-01108 Vilnius, Lithuania \\ E-mail:pozela@pfi.lt
}

Received 16 April 2013; revised 16 May 2013; accepted 20 June 2013

\begin{abstract}
Two types of electrically heated $\mathrm{THz}$ radiation emitters: (1) the Globar-SiC (black body), and (2) the highly doped GaAs plate, are considered as selective high-power terahertz $(\mathrm{THz})$ radiation sources. The spectrum of the new type GaAs emitter in the 9-15 THz frequency range is determined by oscillations of free electron plasma and coupled plasmon-phonons. The thermally stimulated resonant emission of surface plasmon-phonon polaritons is experimentally observed. The radiative modes of coupled surface plasmon-phonon polaritons in the $\mathrm{n}^{+}$-GaAs plate are identified.
\end{abstract}

Keywords: $\mathrm{THz}$ radiation sources, black-body radiation, coupled plasmon-phonon polaritons, $\mathrm{SiC}$, GaAs

PACS: 78.40.Fy, 78.55.Cr, 44.40.+a, 71.36.+c

\section{Introduction}

One of the most exciting areas today to explore scientific and engineering phenomena lies in the terahertz $(\mathrm{THz})$ spectral region. The $\mathrm{THz}$ region of electromagnetic spectrum is of great importance due to rich physical, biological, and chemical processes in this range. The $\mathrm{THz}$ radiation is widely used for non-destructive medical scanning, security screening, quality control, atmospheric investigation, space research, for studies of works in art, etc. [1-8]. One of the key components of any application is the $\mathrm{THz}$ radiation source.

For non-destructive optical testing of conductivity and lattice dielectric function of semiconductor heterostructures as well as for medical imaging applications, the $1-30 \mathrm{THz}$ sources with a high power (typically of $10 \mathrm{~mW})$ and large beam size $\left(\sim 1 \mathrm{~cm}^{2}\right)$ of the emitted beam are needed [5, , , 9, 10].

The aim of our experiments is to propose a compact portable relatively simple $\mathrm{THz}$ source emitting a wide $\mathrm{THz}$ radiation beam with a power density higher than $5 \mathrm{~mW} / \mathrm{cm}^{2}$ in the frequency range of $10-20 \mathrm{THz}$ and a power density higher than $10 \mathrm{~mW} / \mathrm{cm}^{2}$ in the range of $20-30 \mathrm{THz}$.

In this paper, two different types of thermally stimulated $\mathrm{THz}$ radiation emitters are considered: (1) the Globar-SiC whose radiation is close to the black-body emission spectrum and (2) the highly doped $\mathrm{GaAs}$ with the $\mathrm{THz}$ emission spectrum determined by coupled plasmon-phonon oscillations.

\section{Globar-SiC (black-body) $\mathrm{THz}$ radiation emitter}

The most common far infrared sources used up to now have been black-body radiation sources, such as Globars $(\mathrm{SiC})[1-3]$. In our experiment, the $\mathrm{SiC}$ slab of length $L=5 \mathrm{~cm}$ and diameter $d=4.3 \mathrm{~mm}$ was electrically heated up to $950 \mathrm{~K}$. The measured spectrum of the $\mathrm{SiC}$ sample was close to the blackbody spectrum. The intensity of the black-body total radiation estimated from the Planck formula 
at temperature $T=10^{3} \mathrm{~K}$ is $5.6 \mathrm{~W} / \mathrm{cm}^{2}$. The $\mathrm{THz}$ radiation intensity in the $0-15 \mathrm{THz}$ frequency band achieves $10 \mathrm{~mW} / \mathrm{cm}^{2}$, but at the frequency of $1 \mathrm{THz}$, the black-body emitted intensity is only about $10 \mu \mathrm{W} / \mathrm{cm}^{2}$.

However, the main advantage of a Globar (black body) $\mathrm{THz}$ radiation source as compared with other types of $\mathrm{THz}$ radiation sources is an unlimited possibility to increase the size of a hot Globar source and to achieve the highest radiation power density by focusing the radiated power to a smaller area. That allows us to use the Globar-SiC radiation emitters as high-power continuous wave radiation sources with a large-size radiation beam $\left(\sim 1 \mathrm{~cm}^{2}\right)$.

Figure 1 shows a schematic diagram of the experimentally realized $\mathrm{THz}$ radiation source based on the Globar-SiC radiation. The radiation from the Globar-SiC rod electrically heated until $950 \mathrm{~K}$ is directed by the collection system to the waveguide (Al tube with the inner diameter of $9.5 \mathrm{~mm}$ ). The total Globar radiation power collected to the waveguide achieves $0.9 \mathrm{~W}$. To cut a visible part of the Globar radiation, a silicon plate is used. Reflectors and filters are used to select the required $\mathrm{THz}$ frequency range. The $\mathrm{THz}$ radiation output power is measured by the pyroelectric power meter (Vector H410 Scientech Inc.). This radiation power in the 11-33 THz frequency range was measured by using two types of optical filters, $F_{1}$ and $F_{2}$, for 11-22 and 17-33 THz frequency ranges, respectively.

The selection of the $1-20 \mathrm{THz}$ frequency range from the hot Globar radiation spectrum is

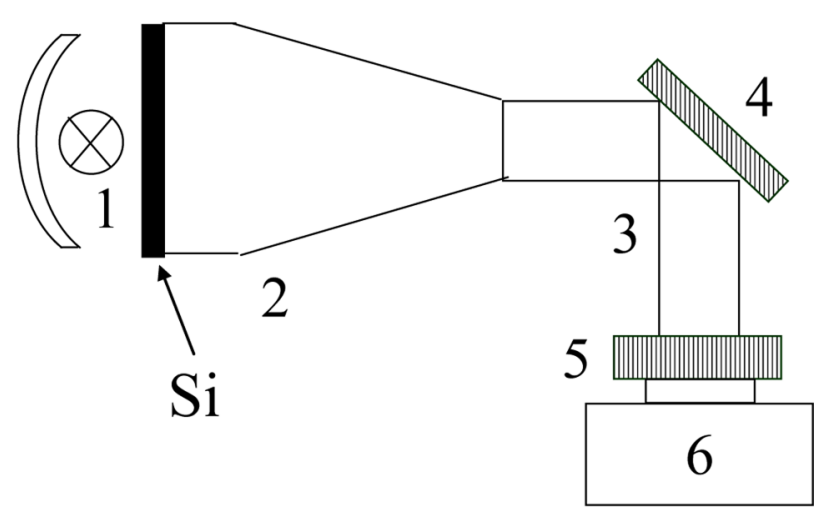

Fig. 1. Set-up of the experiment: 1 Globar-SiC rod, 2 collection system, 3 waveguide (Al tube), 4 T-ray resonant reflectors, 5 T-ray filters, and 6 spectrometer. a complicated problem because most of the materials used as optical elements for the visible and infrared spectra are opaque in that $1-20 \mathrm{THz}$ frequency range. We have proposed [11] to use the known-for-a-long-time Reststrahlen effect in the 5-30 THz frequency range in alkali halides and polar semiconductors. We have used these materials as reflectors (mirrors) with a large reflection area $\left(\sim 1 \mathrm{~cm}^{2}\right)$ for separating the determinate frequency band from the heated-body emission spectra [11].

Table shows the experimentally observed $\mathrm{THz}$ source output power data dependently on the reflector type: the total power (without filters) of Globar radiation $P_{\text {total }}$ and powers $P_{1}$ and $P_{2}$ in the 11-22 and 17-33 THz frequency ranges, respectively.

Table 1. Experimental data of the $\mathrm{THz}$ source output power.

\begin{tabular}{c|c|c|c}
\hline Reflector & $\begin{array}{c}\text { Total output } \\
\text { power }\end{array}$ & $\begin{array}{c}\text { Filter } F_{1} \\
11-21 \\
(\mathrm{THz})\end{array}$ & $\begin{array}{c}\text { Filter } F_{2} \\
17-33^{2} \\
(\mathrm{THz})\end{array}$ \\
\hline & $P_{\text {total }}(\mathrm{mW})$ & $P_{1}(\mathrm{~mW})$ & $P_{2}(\mathrm{~mW})$ \\
\hline $\mathrm{Al}$ & 200 & 6.4 & 19.8 \\
\hline Sapphire & 33 & 5 & 10.6 \\
\hline $\mathrm{CaF}_{2}$ & 21 & 3.4 & 4 \\
\hline $\mathrm{BaF}_{2}$ & 21 & 1 & 2.6 \\
\hline $\mathrm{GaAs}$ & 82 & 4.4 & 8.4 \\
\hline $\mathrm{InSb}$ & 71 & 3 & 8.8 \\
\hline
\end{tabular}

In the case of the Al-coated reflector, the observed total output power of the Globar radiation collected in the waveguide after the Si-filter is equal to $200 \mathrm{~mW}$ and the power values in the $\mathrm{THz}$ frequency range selected by the filters are $P_{1}=6.4 \mathrm{~mW}$ and $P_{2}=19.8 \mathrm{~mW}$. In the range of 11-33 THz, the collected power part of the Globar radiation can be estimated as $13 \%$. In cases of $\mathrm{BaF}_{2}, \mathrm{CaF}_{2}$, and sapphire $\left(\alpha-\mathrm{Al}_{2} \mathrm{O}_{3}\right)$ reflectors with low high-frequency refractive indexes, the reflected output power decreases up to $21-33 \mathrm{~mW}$. However, a strong increase in the $\mathrm{THz}$ radiation part selected by the filters from the total collected radiation takes place. In the case of the sapphire reflectors, half of the reflected Globar radiation power belongs to the $11-33 \mathrm{THz}$ spectrum part. In cases of $\mathrm{CaF}_{2}$ and $\mathrm{BaF}_{2}$ reflectors, the cuts of high-frequency parts of the Globar radiation take place at 12 and $16 \mathrm{THz}$, respectively. Due to this 
reason, the observed radiation power in the frequency range selected by the filters is low. In cases of $\mathrm{GaAs}$ and InSb reflectors, the total output power increases up to 70-82 $\mathrm{mW}$ due to large high-frequency refractive indexes, and the $11-33 \mathrm{THz}$ part of the radiation power output is less than $17 \%$.

One can see that the observed output power in the 11-33 THz frequency range achieves $12-25 \mathrm{~mW}$ at the collected Globar source total output power of $200 \mathrm{~mW}$. Therefore, it is shown that a higher power level of the $\mathrm{THz}$ source can be achieved by the value of Globar output power which has to exceed $200 \mathrm{~mW}$. Thus, a large radiation power in the $\mathrm{THz}$ frequency range allows us (using the Reststrahlen effect) to select the narrow frequency line $(\Delta v=1 \mathrm{THz})$ with a sufficiently high power $\left(10^{-3} \mathrm{~W}\right)$.

\section{GaAs as a selective $\mathrm{THz}$ radiation emitter}

The heated single crystal GaAs plates made of Tedoped $350 \mu \mathrm{m}$ thick polished wafers are investigated as $\mathrm{THz}$ radiation emitters. The measured total emitted power density of a GaAs plate with the size of $8 \times 20 \mathrm{~mm}^{2}$ exceeds $20 \mathrm{~mW}$ at $150{ }^{\circ} \mathrm{C}$. However, the emitted radiation spectra of the heated GaAs plate in the $\mathrm{THz}$ frequency range differ from the black-body radiation spectra.

The GaAs plate was heated by electric current. The thermally stimulated $\mathrm{THz}$ emission spectra were measured by the IR Fourier transformerspectrometer (Thermo Scientific Inc. Nicolet 8700). It is found that the resonant reflection as well as emission of the $\mathrm{THz}$ radiation depends on temperature of the GaAs plate.

Figure 2 shows the measured reflection spectra of three samples of conductive $\mathrm{n}^{+}-\mathrm{GaAs}$ with high density of free electrons in comparison with the reflection spectrum of semi-insulating (SI) GaAs.

We can see that SI GaAs has a sharp resonant reflection peak, which corresponds to the transverse optical (TO) phonon frequency $\omega_{\mathrm{T}}$ and sharp reflection minimum, which corresponds to the longitudinal optical (LO) phonon frequency $\omega_{\mathrm{L}}$.

The $\mathrm{THz}$ reflection spectra of high-conductivity $\mathrm{n}^{+}$-GaAs are quite different from those of SI GaAs. A large increase in the reflection in a wide radiation frequency band in comparison with the reflection in the SI GaAs case is accompanied by two dips in

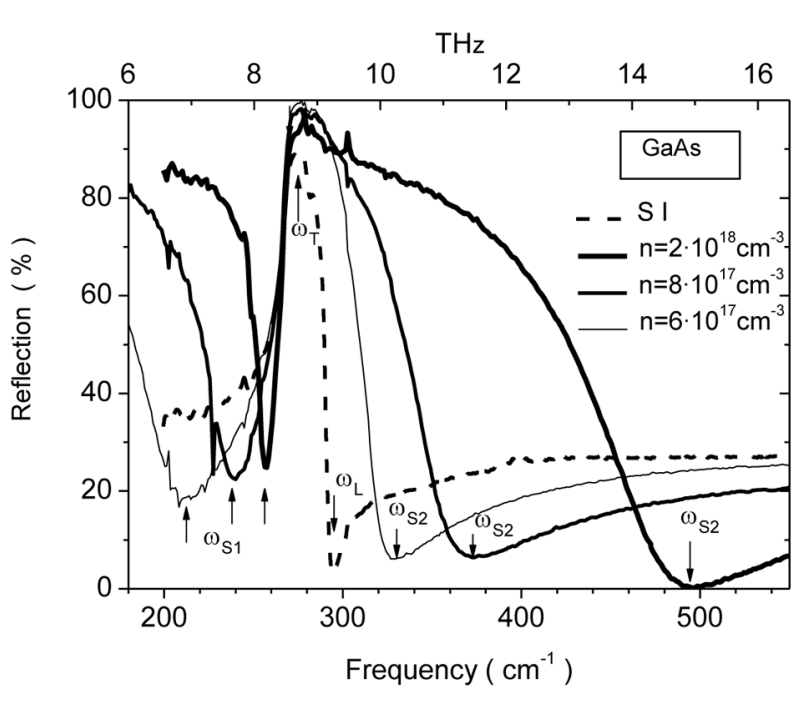

Fig. 2. THz reflection spectra of the SI and doped GaAs plates with electron densities: $6 \times 10^{17}, 8 \times 10^{17}$, and $2 \times 10^{18} \mathrm{~cm}^{-3}$ at $T=300 \mathrm{~K}$. The frequencies of minimal reflection, $\omega_{\mathrm{S} 1}$ and $\omega_{\mathrm{S} 2}$, are shown by arrows.

reflection spectra (labelled as $\omega_{\mathrm{S} 1}$ and $\omega_{\mathrm{S} 2}$ ) for every doped samples. The frequency of reflection minimum $\omega_{s 1}$ is near the GaAs bulk TO phonon frequency. The frequency $\omega_{\mathrm{s} 2}$ is larger than the bulk LO phonon frequency and increases with increasing the free electron density in GaAs. At frequencies $\omega<\omega_{\text {S1 }}$, the experimentally observed reflection increases.

The interaction of free electron plasma and phonon oscillations with the $\mathrm{THz}$ radiation is responsible for significant changes in these spectra [3, 9, 12, 13,. The coupling between infrared-active optical phonons, plasmons, and electromagnetic waves can be so strong that they cannot be separated inside the medium. Instead, they should be regarded as coupled waves or quasiparticles known as plasmon-phonon polaritons. These longitudinal oscillations are known as the coupled plasmon-LO phonon modes [3, 12, 13].

Note that the resonance in the reflectivity spectra of highly doped GaAs with $\omega_{\mathrm{P}}^{2}>\omega_{\mathrm{L}}^{2}$ does not equal the LO or TO phonon frequency as well as plasma frequency $\omega_{\mathrm{p}}$ but is determined by the specific coupled plasmon-phonon oscillations.

Assuming that the interaction of $\mathrm{THz}$ radiation with the surface plasmon-phonon oscillations is responsible for the peaks of low reflectivity $\omega_{\mathrm{s}}$, the frequency $\omega_{\mathrm{S}}$ can be estimated from the equation

$$
\varepsilon\left(\omega_{\mathrm{S}}\right)+1=0,
$$


where the dielectric function of highly doped GaAs is equal to [3, 12]

$$
\varepsilon(\omega)=\varepsilon_{\infty}\left(\frac{\omega^{2}-\omega_{\mathrm{L}}^{2}}{\omega^{2}-\omega_{\mathrm{T}}^{2}}-\frac{\omega_{\mathrm{p}}^{2}}{\omega^{2}}\right),
$$

where $\omega_{\mathrm{p}}$ is the free electron plasma oscillation frequency in GaAs. Assuming $\omega_{\mathrm{p}} \approx 420 \mathrm{~cm}^{-1}$, we obtain $\omega_{\mathrm{s} 1} \approx 250$ and $\omega_{\mathrm{s} 2} \approx 423 \mathrm{~cm}^{-1}$. This coincides with the experimentally observed data and confirms that the frequencies of reflection resonances $\omega_{\mathrm{S} 1}$ and $\omega_{\mathrm{S} 1}$ are determined by the interaction of the $\mathrm{THz}$ radiation with surface plasmon-phonon polaritons.

It is predicted $[3,12,13]$ that at

$$
\varepsilon(\omega)=0,
$$

the resonant coupled plasmon-phonon oscillations are emitted from $\mathrm{GaAs}$ in the $\mathrm{THz}$ spectral range. The self-sustaining resonant oscillation at $\varepsilon=0$ appears in the absence of incident $\mathrm{THz}$ radiation. Thus, the specific plasmon-phonon oscillation is not excited by an electric field of incident $\mathrm{THz}$ radiation. The electromagnetic field created by thermal vibrations of atoms can "leave" a crystal under certain conditions and be recorded as thermal emission of a nonblack body [3, 13].

We used the dependence of the plasmon-phonon radiation intensity on the crystal temperature for identification of radiated modes of plasmonphonon oscillations. The thermally stimulated $\mathrm{THz}$ emission and reflection spectra of the highly doped GaAs plate were measured.

Figure 3 shows the radiation spectra of thermally stimulated $\mathrm{THz}$ emission power $P$ of the heated highly doped GaAs plate. One can see that two resonant emission peaks are experimentally observed at the frequencies of 250 and $450 \mathrm{~cm}^{-1}$. Note that the emission spectra are modulated by sharp spikes caused by the interaction of $\mathrm{THz}$ radiation with water vapours in the air.

Note that the experimentally measured $\mathrm{THz}$ radiation resonant frequencies $\omega_{\text {rad }}$ coincide with the theoretically calculated ones of bulk plasmonphonon oscillations in GaAs. The frequency $\omega_{\text {rad }}$ of the bulk plasmon-phonon polariton is determined by the equation $\varepsilon\left(\omega_{\text {rad }}\right)=0$. The estimated values are $\omega_{\text {rad1 }}=253$ and $\omega_{\text {rad2 }}=442 \mathrm{~cm}^{-1}$ for $\omega_{\mathrm{P}} \approx 420 \mathrm{~cm}^{-1}$.

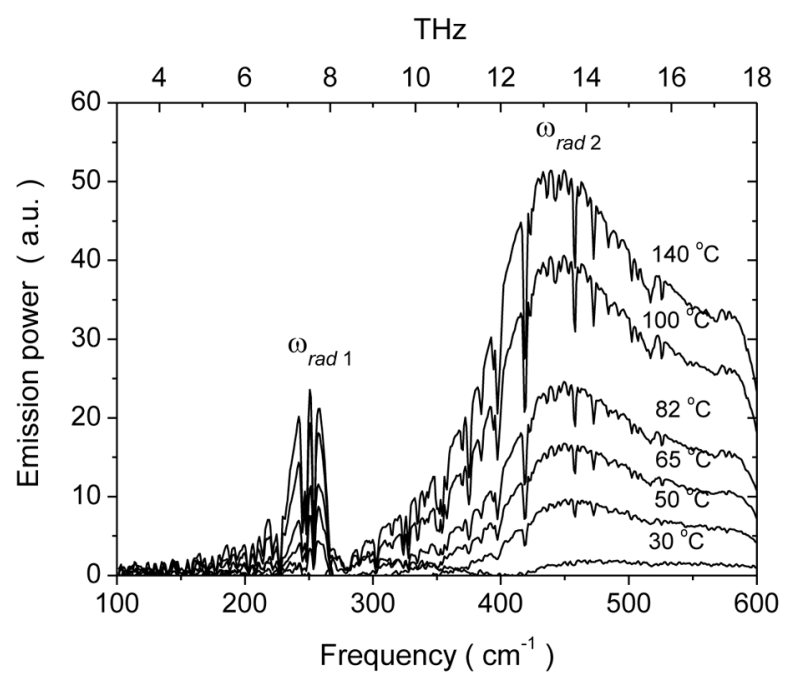

Fig. 3. THz emission power spectra of the heated highly doped GaAs plate at different temperatures.

One can see that the intensity of $\mathrm{THz}$ resonant radiation at resonance frequencies increases with increasing GaAs temperature. The intensity of the $\mathrm{THz}$ resonant radiation outside the resonant peaks is very small. However, a slow increase in intensity with radiation frequency increasing is observed. It coincides with the increase in black-body radiation intensity.

The total power density of the emitted radiation of the GaAs plate heated at $250^{\circ} \mathrm{C}$ exceeds $40 \mathrm{~mW} / \mathrm{cm}^{2}$. This means that the heated GaAs sources with selected 7.6 and $13.3 \mathrm{THz}$ frequencies can be used as high-power continuous wave $\mathrm{THz}$ radiation sources.

\section{Conclusions}

Two types of heated emitters, Globar-SiC and highly doped GaAs plate, are considered for generation of high-power $\mathrm{THz}$ radiation. The compact portable high-power $\mathrm{THz}$ radiation source useful for studying interaction of high-power $\mathrm{THz}$ radiation with elemental $\mathrm{THz}$ excitations in solids (phonons, plasmons) and with molecular oscillation excitations in biological materials is realized. The new type selective continuous wave $\mathrm{THz}$ radiation source in the $5-15 \mathrm{THz}$ frequency range based on the radiative modes of coupled plasmon-phonon oscillations in the highly doped GaAs plate is proposed. The thermally stimulated 
resonant plasmon-phonon radiation of the highly doped GaAs is experimentally observed.

\section{Acknowledgements}

This research was supported by the Research Council of Lithuania (Grant No. MIP-59/2013).

\section{References}

[1] X.-C. Zhang and J. Xu, Introduction to THz Wave Photonics (Springer, Berlin, 2010).

[2] Y.-S. Lee, Principles of Terahertz Science and Technology (Springer, Berlin, 2009).

[3] V.M. Agranovich and D.L. Mills (eds.), Surface Polaritons (North Holland, Amsterdam, 1982).

[4] A. Krotkus, Semiconductors for terahertz photonics applications, J. Phys. D: Appl. Phys. 43, 273001 (2010), http://dx.doi.org/10.1088/0022$3727 / 43 / 27 / 273001$

[5] Y. Miura, A. Kamataki, M. Uzuki, T. Sasaki, J. Nishizawa, and T. Sawai, Terahertz-wave spectroscopy for precise histopathological imaging of tumor and non-tumor lesions in paraffin sections, Tohoku J. Exp. Med. 223, 291 (2011).

[6] G. Filippidis, M. Massaouti, A. Selimis, E.J. Gualda, J.-M. Manceau, and S. Tzortzakis, Nonlinear imaging and $\mathrm{THz}$ diagnostic tools in the service of Cultural Heritage, Appl. Phys. A 106, 257-263 (2012), http://dx.doi.org/10.1007/s00339-011-6691-7
[7] P. Shumyatsky and R.R. Alfano, Terahertz sources, J. Biomed. Opt. 16, 033001-033001-9 (2011), http://dx.doi.org/10.1117/1.3554742

[8] W. Knap, H. Videlier, S. Nadar, D. Coquillat, N. Dyakonova, F. Teppe, M. Bialek, M. Grynberg, K. Karpierz, J. Lusakowski, K. Nogajewski, D. Seliuta, I. Kašalynas, and G. Valušis, Field effect transistors for terahertz detection - silicon versus III-V materials issue, Opto-Electronics Rev. 18(3), 225-230 (2010), http://dx.doi. org/10.2478/s11772-010-1018-7

[9] J. Požela, K. Požela, A. Silėnas, E. Širmulis, and V. Juciené, Interaction of terahertz radiation with surface and interface plasmon-phonons in $\mathrm{AlGaAs} / \mathrm{GaAs}$ and $\mathrm{GaN} / \mathrm{Al}_{2} \mathrm{O}_{3}$ heterostructures, Appl. Phys. A 110, 153-156 (2013), http://dx.doi. org/10.1007/s00339-012-7473-6

[10] J. Lloyd-Hughes and T.-I. Jeon, A review of the terahertz conductivity of bulk and nano-materials, J. Infrared Milli Terahz Waves 33, 871-925 (2012), http://dx.doi.org/10.1007/s10762-012-9905-y

[11]J. Požela, E. Sirmulis, K. Požela, A. Silènas, and V. Juciené, New type of $5-22 \mathrm{THz}$ radiation sources based on semiconductor resonant reflectors, Phys. Status Solidi C 9, 1696-1698 (2012). http://dx.doi.org/10.1002/pssc.201100641

[12] P.Y. Yu and M. Cardona, Fundamentals of Semiconductors (Springer, Berlin, 2005) pp. 298303, 339 .

[13] M. Cardona, Fresnel reflection and surface plasmons, Am. J. Phys. 39, 1277 (1971), http://dx.doi. org/10.1119/1.1976627

\title{
SELEKTYVŪS TERAHERCŲ SPINDULIUOTĖS ŠALTINIAI SU SiC IR GaAs EMITERIAIS
}

\author{
J. Požela, E. Širmulis, K. Požela, A. Šilènas, V. Jucienè \\ Fiziniu ir technologijos moksly centro Puslaidininkiu fizikos institutas, Vilnius, Lietuva
}

\section{Santrauka}

Nagrinèjami dviejų tipų emiteriai: 1) SiC spinduolis-globaras (juodas kūnas) ir 2) stipriai legiruota GaAs plokštelè, kaip selektyvūs didelès galios terahercų $(\mathrm{THz})$ spinduliuotes šaltiniai. Naujo tipo GaAs emiterio spektras 9-15 THz dažnių ruože yra sąlygojamas laisvųjų elektronu plazmos ir surištu plazmon-fononu osciliacijomis. Eksperimentiškai stebèta termostimuliuota paviršinių plazmon-fonon-poliaritonų rezonansinè $\mathrm{THz}$ emisija. Identifikuotos paviršinių plazmon-fononpoliaritonų spindulinès modos $\mathrm{n}^{+}-\mathrm{GaAs}$ plokšteleje. 